\title{
Role of health extension workers in the relationship between vector control interventions and malaria in Ethiopia
}

\author{
Mohammed Aliye ${ }^{1}$ and Tao Hong ${ }^{2 *}$
}

\begin{abstract}
Background: Despite a tremendous decline in the burden of malaria through public health interventions, it is yet remains a critical parasitic health problem in Ethiopia. Insecticide-treated nets and indoor residual spray are considered as the most effective preventive interventions against malaria. This study intended to determine the role of health extension workers in influencing the relationship between vector control strategies and malaria prevalence in Ethiopia.

Methods: The study adopted a descriptive study based on panel data collected from 10 regions of Ethiopia from 2010 to 2018. The data collected were analyzed using STATA version 13.0. Structural equation modelling was used to assess the mediating effect of health extension workers in the relationship. Further, the random effect model was employed to investigate the direct relationship among the study variables.
\end{abstract}

Results: We observed a strong mediating role of health extension workers to the relationship between strategic interventions and malaria prevalence, where the direct path is $(\beta=0.64, p<0.05)$, and the indirect path $(\beta=0.72$, $p<0.001)$ and $(\beta=0.98, p<0.001)$ confirming the mediation condition to appear. Our analysis revealed that, insecticide-treated nets and indoor residual spray significantly impacts the malaria prevalence $(\beta=0.20, p<0.05)$ and $(\beta=0.70, p<0.001)$ respectively. Further, our analysis suggests that the cumulative effect of indoor residual spray and insecticide-treated mosquito nets have helped better avert malaria prevalence $(\beta=81.3 \%, P<0.05)$. Moreover, the finding demonstrates the incremental rate of $30.2 \%$, which is the indirect effect of the research $[(\beta=$ $0.813)-(\beta 1=0.511)]$.

Conclusion: The findings are potentially useful for the health sector in charge of infectious disease prevention and control, particularly in developing countries explaining how these group provided support to reduce malaria ensuring the provision of proper health message about the program.

Keywords: Malaria prevalence, Strategic interventions, Health extension workers, Structural equation modeling

\footnotetext{
* Correspondence: hongtao@hit.edu.cn

${ }^{2}$ Harbin Institute of Technology, Harbin, Heilongjiang province, China

Full list of author information is available at the end of the article
} 


\section{Background}

Malaria is the most critical parasitic health problem in tropical regions $[1,2]$, a leading cause of morbidity and preventable death [3-6]. Remarkable success is documented in the fight against malaria, especially in Africa $[2,7]$. Nevertheless, malaria remains a global health challenge that causes massive morbidity and poses a higher burden of the disease [8]; nearly half of the population of the world lives in the malaria-endemic area [9]. In 2015 the World Health Organization (WHO) estimated that malaria caused 212 million cases worldwide, leading to approximately 429,000 deaths. Africa is the most affected continent with $92 \%$ of all malaria deaths mainly occur in children under 5 years [10]. Malaria has been identified as a public health issue in Sub-Saharan Africa, especially in pregnant women and children with the highest risk of severe illness and death [11, 12]. The Ethiopian population has affected by malaria during the planting and harvesting season, causing a decrease in the productive capacity when there is a greater need for work [13, 14]. In 2017, there were more than 1.7 million confirmed malaria cases and recorded as the top ten cause of morbidity among children under 5 years (2.3\%) [15]. Likewise, it was the leading cause of outpatient, admission, and death [16]. The Ethiopian health sector has introduced a three-tier health care delivery system, characterized by a Primary Health Care Unit (PHCU); where level one is a Woreda/District health system comprised of a primary hospital (to cover 60,000-100,000 people), health centers (1/15,000-25,000 population) and their satellite Health Posts that serve a kebele comprising (1/ 3000-5000 population) connected by a referral system. Level two is a General Hospital covering a population of 1-1.5 million people, and level three is a Specialised Hospital covering a population of $3.5-5$ million people [17]. PHCU is the lowest level in the Ethiopian health system. A health post is an operational center for two HEWs, which serves 3000-5000 people. A kebele is the smallest administrative unit in Ethiopia, but it can include several small villages. The Ethiopian government has been deploying trained new cadres named health extension workers since 2003, and by the year 2010, a total of 33,819 HEWs were trained and deployed throughout the country, which are required to spend $75 \%$ of their time conducting out-reach activities visiting house to house to their respective kebele, while the rest of their time are supposed to be at the health post [18]. Many studies investigated vector control strategy (ITNs and IRS) ownership and use for malaria prevention [19-26], and have suggested possible benefits attributable to malaria control, such as the association of ITNs use with malaria knowledge and connection of malaria prevalence with malaria control interventions. Most of these studies relying on cross-sectional data of the specific communities. Moreover, community health workers have identified enhancing the preventive capacity and improve provider-patient linkage [27-30].

Nonetheless, none of the studies recognized the contribution of health extension workers to the relationship between vector control interventions and malaria prevalence. Besides, the previous research fails to add health workers to contribute to the malaria programme in particular. For Ethiopia, ITNS and IRS were hampered by knowledge gaps about malaria transmission, low utilization, and misunderstandings. Therefore, this study aimed at investigating the mediating role of unstudied health extension workers to the improvement of the relationships between ITNs, IRS, and malaria prevalence by employing Structural Equation Modelling (SEM) and by using the period from 2010 to 2018. The study also uses the Random Effect Model (REM) to assess the direct effect of ITNs and IRS on malaria. Also, the study is designed to provide concentrate and adequate evidence to advise malaria prevention and control in this area.

\section{Health extension workers and malaria}

Indications that health extension workers positively impact the relationship between intervention approach and malaria, connected to the preventive characteristics of malaria disease. In Ethiopia, $68 \%$ of the landmass is a malarious area, and about $60 \%$ of the population is at risk of malaria infection $[14,31]$. Insecticide-treated mosquito nets (ITNs) and indoor residual spraying (IRS) were identified as a key approach because of the effectiveness of malaria prevention [32]. Ethiopia is the first country to adopt the scale-up for impact concept (SUFI) for malaria control, and about 50 million insecticidetreated mosquito nets distributed since 2005, and indoor residual spraying scaled up into targeted areas [33]. However, variations on intervention coverage at different sites and problems related to ownership and use of ITNs were reported [34, 35]. Despite the reduction in global malaria cases and deaths [7, 36], challenges with the community's awareness about net care, use, and repair were reported [37]. Community participation and a responsive approach to malaria control have reported increasing intervention take-up [38]. Community health workers are recognized as an integral part of primary health-care teams, especially in poor and underserved populations [39]. World health organization (WHO) launched "Treat, Train, and retain," coordinated global effort to address the shortage of health workers across different disease programs, particularly in low-andmiddle-income countries [40]. Health workers are defined to be all people engaged in actions whose primary intent is to enhance health, such as physicians, nurses, midwives, public health professionals, community health workers, and all other support workers [41, 42]. For 
infectious disease prevention and control to succeed, community participation is vital, where vulnerable groups share similar goals. The provision of training skills for community health workers has been reported affecting the transfer of information and treatment of malaria to their respective communities [43]. WHO recognized the creation of capable, motivated, and supported health workers achieving national and global health goals and addressing bottlenecks [44]. Furthermore, community health workers give their clients a way to prevent illness and treat chronic disease [45].

In 2003, Ethiopia initiated the rapid expansion of primary health coverage through a comprehensive health extension program in response to the country's health problems like malaria. Thus, 10th-grade female high-school graduates were recruited from the area who trained for a full year and returned to the community to promote health and provide village-level services [46]. Two HEWs partnered to represent between 3000 to 5000 people at the health-post level, where they devote much of their time to home visits and outreach. The primary health coverage mostly includes the prevention and control of infectious disease, which is prevented and controlled if accessible intervention tools are utilized by the community. So, the role of health extension workers is to work closely in the society about health promotion and disease prevention, creating awareness on the vulnerability and severity of the disease-the following four hypotheses derived on the basis of the above logical arguments and literature discussions.
H1: Strategic intervention is significantly related to malaria prevalence.

$\mathrm{H} 2$ : Strategic intervention is positively related to health extension workers.

H3: Health extension workers are positively associated with malaria prevalence.

H4: Health extension workers mediate the relationship between intervention strategy and malaria prevalence

(Fig. 1).

\section{Methods}

Study design, data collection, and study variables

Administratively Ethiopia is structured into nine regional states - Tigray, Affar, Amhara, Oromiya, Somali, Benishangul-gumuz, Southern Nations Nationalities and Peoples (SNNP), Gambela, and Harari and two city administrations, Addis Ababa and Dire Dawa [47]. Thus, a descriptive study based on panel data of 10 endemic entities excluding Addis Ababa was adopted to investigate the relationship between vector control interventions (IRS, ITNs) and malaria prevalence as health extension workers play a mediating role, using national-level data from health and health-related indicators (HHI), fielded annually from 2010 to 2018 . The hypotheses above were tested using data collected by the Ethiopian Federal Ministry of Health, in collaboration with the regional health bureau and other stakeholders. HHI includes detailed descriptions of variables related to the malaria program, primarily the prevalence of malaria, deaths of malaria, health workforce, health service expansion, health expenditure, and vector control interventions

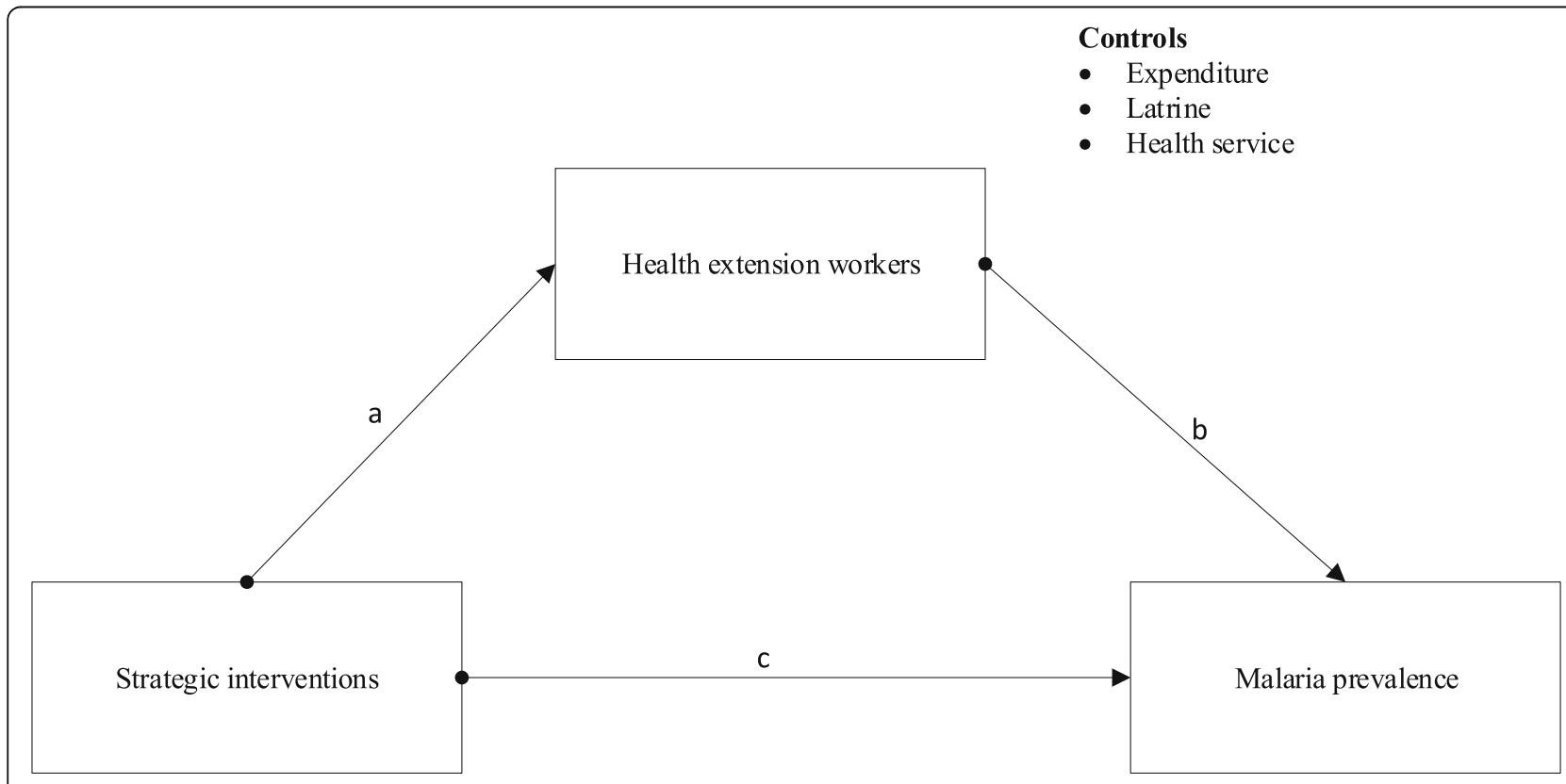

Fig. 1 Research model 
[47]. After the relevant variables were identified for the current study, we condensed our data as suitable, containing 90 observations.

\section{Analysis}

Social science statistical package, STATA Version 13.0, was used to analyze the data. We followed a two-step approach to conduct the analysis. The paths of hypotheses between constructs were first estimated using the structural equation model (SEM) followed by random effect model (RAM) testing.

\section{Model testing}

All of the hypothesized relationships were examined using structural equation modeling (SEM). SEM method is favored in the causal modeling method as it allows measurement error control, provides information on the degree of fit of the examined model [48]. We tested the theoretical framework in two steps. First, the theoretical framework was examined through the proposed linear relationships among the study variables as well as the mediating effect (hypotheses 1-4) at once in the same model (model 1). Second, the random-effect model (REM) is used to check the direct influence of independent variables on the outcome variable in line with controlling factors (model 2), where REM has the advantage of higher efficiency compared to the FEM resulting in smaller standard errors of coefficients. And high statistical power to detecting effects [49].

Various models were developed to test the direct, indirect, and mediating effect of the study variables. Equation (1) was designed to test the direct influence of indoor residual spraying and insecticide-treated mosquito nets on malaria disease. Equation (2) is designed to test the relationship between health extension workers and vector control measures. Equation (3) for testing the effect of health extension workers on the outcome variable. Equation (4) is used to prove the influence of independent and mediating factors on the outcome of malaria. Eq. (5a\&b) and (6) proves the indirect impact of the factors on the relationship. The model uses the log of all variables to minimize data variances. The principal component analysis is also used to capture multiple indicators of our dependent variables and health service expansion. Thus, various models presented as follows:

$$
\begin{aligned}
& y=\beta_{0}+\beta_{1} X+\varepsilon \\
& M=\beta_{0}+\beta_{1} X+\varepsilon \\
& Y=\beta_{0}+\beta_{1} M+\varepsilon \\
& Y=\beta_{0}+\beta_{1} X+\beta_{2} M+\varepsilon
\end{aligned}
$$

To test the indirect effect of the factor in our study, the following two models derived from the above main study equations as follows:

$$
\begin{aligned}
& \text { Model 1. } Y=\beta_{0}+\beta_{1} X+\beta_{0} M+\varepsilon \\
& \text { Model 2. } Y=\beta_{0}+\beta X+\varepsilon
\end{aligned}
$$

Then, by subtracting $\beta 1$ from $\beta$, we estimate the indirect effect given by:

$$
\beta_{\text {indirect }}=\beta-\beta_{1}
$$

Where Y represents a dependent variable (malaria prevalence), determined as confirmed malaria cases for both Plasmodium species in all age groups [31, 50, 51], $\mathrm{X}$ is an independent variable (strategic interventions), calculated for all regions during the 9 years accordingly, and $\mathrm{M}$ represents a mediating variable calculated for all study regions, health service expansion, health expenditure, and latrine coverage as a control variable during the study period. While is the mean, the timeinvariant component of those variables [52], $\beta$ is an estimate of the within effect, and e is the error term. All variables and correlations were found to be significant if $p<0.05$.

\section{Results \\ Descriptive analysis}

The author has empirically investigated 90 observations from 10 malaria epidemic regions of Ethiopia. Data in Table 1 shows descriptive details, i.e., the means (M), standard deviations (SD), and correlations among the study variables. Correlation analysis showed that all of the study variables were positively and significantly associated with each other. All of the associations between the study variables were in the expected directions.

\section{Hypothesis results}

The first step involved addressing the effect of the strategic intervention on malaria prevalence and health extension workers. We checked four steps involved in the Baron and Kenny approach for the establishment of mediation [53]. To establish mediation, 1) the relationship between independent and outcome variable should be significant; 2) significant relationship between independent variable to the hypothesized mediating variable; 3 ) the mediating variable should be significantly related to the dependent variable, where both the independent and mediating variable is predictors of the dependent variable; 4) a positive coefficient anticipated for the indirect impact of the study, and also a larger coefficient relating independent variable to dependent variable anticipated. The proposed direct and indirect relationships (hypothesis 1-4) were simultaneously tested in the structural equation model. The results are depicted in Table 2 (model 1). Consistent with the researcher's anticipation of a positive relationship between strategic intervention and malaria prevalence, the path was found to be 
Table 1 Descriptive statistics of the research variable

\begin{tabular}{|c|c|c|c|c|c|c|c|c|}
\hline & $M$ & SD & Malaria & Intervention & HEWs & $\mathrm{HE}$ & LC & HSE \\
\hline$M P$ & 9.667052 & 2.739 & 1.0000 & & & & & \\
\hline Interventions & 11.39936 & 0.536 & $0.4910^{*}$ & 1.0000 & & & & \\
\hline HEWS & 3 & 1.000 & $0.6112^{*}$ & $0.5311^{*}$ & 1.0000 & & & \\
\hline$H E$ & 6.911924 & 1.502 & $0.5827^{*}$ & $0.4507^{*}$ & $0.8107^{*}$ & 1.0000 & & \\
\hline$L C$ & 11.90568 & 2.932 & $0.4229^{*}$ & $0.4154^{*}$ & $0.7531^{*}$ & $0.5529^{*}$ & 1.0000 & \\
\hline HSE & 2.000001 & 1.000 & $0.5803^{*}$ & $0.4186^{*}$ & $0.8497^{*}$ & $0.8282^{*}$ & $0.7546^{*}$ & 1.0000 \\
\hline
\end{tabular}

Note: MP represents malaria prevalence; HEWs represents health extension workers; $H E$ represents health expenditure; $H S E$ represents health service expansion; $L C$ represents latrine coverage. $M$ Mean, $S D$ standard deviation, ${ }^{*} p<0.05$

significant $(\beta=0.64, p<0.05)$. It was concluded that strategic intervention has a direct positive effect on the prevalence of malaria; thus, $\mathrm{H} 1$ and condition 1 was accepted. The researchers also attempted to determine whether a strategic intervention has a positive influence on health extension workers. As proposed, the path coefficient was positive $(\beta=0.98)$ and statistically significant $(p<0.000)$, supporting the $\mathrm{H} 2$ notion and meeting condition 2. Moreover, health extension workers had a significant effect on malaria prevalence $(\beta=0.72, p<$ 0.001 ), supporting hypothesis 3 , fulfilling condition 3 . Finally, the researcher addresses the mediating effect of health extension workers in line with the direct impact, where path $\mathrm{a}+\mathrm{b}$ is the indirect effect, and path $\mathrm{c}$ is the direct effect. Consistent with the study expectation of a positive relationship between independent and dependent variables via mediator, the path was found to be significant, where path a $(\beta=0.98, p<0.001)$, path $\mathrm{b}$ $(\beta=0.72 .3, p<0.001)$ and path $\mathrm{c}(\beta=0.64, p<0.05)$. Thus, hypothesis 4 regarding the mediation effect was supported. Likewise, a positive coefficient for the indirect path $(\beta=0.30)$, and a larger coefficient of independent to dependent relationship existed $(\beta=0.81, p<0.05)$, $(\beta 1=0.51, p<0.05)$ meeting the 4th mediation analysis approach. The study also shows the significant role of health extension workers in the relationship between strategic interventions and malaria prevalence with $74 \%$ $(0.98+0.43-0.67)$ if mediation effect in place, and 0.67 without mediation.

\section{Results of the direct relationship}

Table 3 presents a detailed description of associations between research variables. Thus, the results of a random effect model regressions offered to show the relationship between dependent, mediating, and independent variables. The effect of control variables on the outcome of malaria was also presented. The model provides an assessment of vector control methods (IRS \& ITNs) and health extension workers to impact malaria prevalence. The result showed a positive relationship between strategic intervention and malaria prevalence $(\beta=81.3, p<0.01)$, which indicates strategic mechanisms conquer malaria control at model 1 . A significant relationship reported on the impact of intervention on malaria prevalence revealing the attribution of the strategy to prevent malaria $(\beta=0.511, p<0.05$, and $\beta=0.487, p<$ $0.05)$ as shown in model 2 and 3 respectively. Moreover, the study demonstrates the positive association of controlling factors such as health service expansion and health expenditure to malaria prevalence, with a significant value at 0.1 . Further, a negative relationship was reported for latrine coverage, revealing an indirect effect of this factor on malaria prevention actions.- Supported by the report that showed the indirect effect of latrine coverage on the malaria program due to the reduction in the accumulation of dust around households, which paves the way for reduced malaria transmission [54]. Moreover, the research revealed differences in the attribution of malaria prevention when two independent

Table 2 Results of Structural Equation Model Path Analysis

\begin{tabular}{|c|c|c|c|c|c|c|c|}
\hline \multirow[b]{2}{*}{ Controls } & \multirow[t]{2}{*}{ Path } & \multirow[t]{2}{*}{ Coefficient } & \multirow[t]{2}{*}{ SE } & \multirow[t]{2}{*}{ 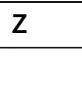 } & \multirow[t]{2}{*}{$\mathbf{P}$} & \multicolumn{2}{|c|}{ [95\% Conf. Interval] } \\
\hline & & & & & & & \\
\hline Malaria prevalence $<-$ & Health expenditure & .2065569 & .2951408 & 0.70 & 0.484 & -.3719084 & .7850223 \\
\hline Malaria prevalence <- & Laterine coverage & -.1371008 & .1269505 & -1.08 & 0.280 & -.3859193 & .1117176 \\
\hline Malaria prevalence <- & H/S/expansion & .6890804 & .5170457 & 1.33 & 0.183 & -.3243106 & 1.702471 \\
\hline \multicolumn{8}{|l|}{ Main Effects } \\
\hline Malaria prevalence <- & Interventions & .6350601 & .261278 & 2.43 & 0.015 & .1229646 & 1.147156 \\
\hline Malaria prevalence $<-$ & HEWs & .722892 & .1412621 & 5.12 & 0.000 & .4460233 & .9997607 \\
\hline HEWs $<-$ & Interventions & .9822345 & .165201 & 5.95 & 0.000 & .6584465 & 1.306023 \\
\hline
\end{tabular}

Note: HEWs denotes health extension workers 
Table 3 Result of the direct relationship

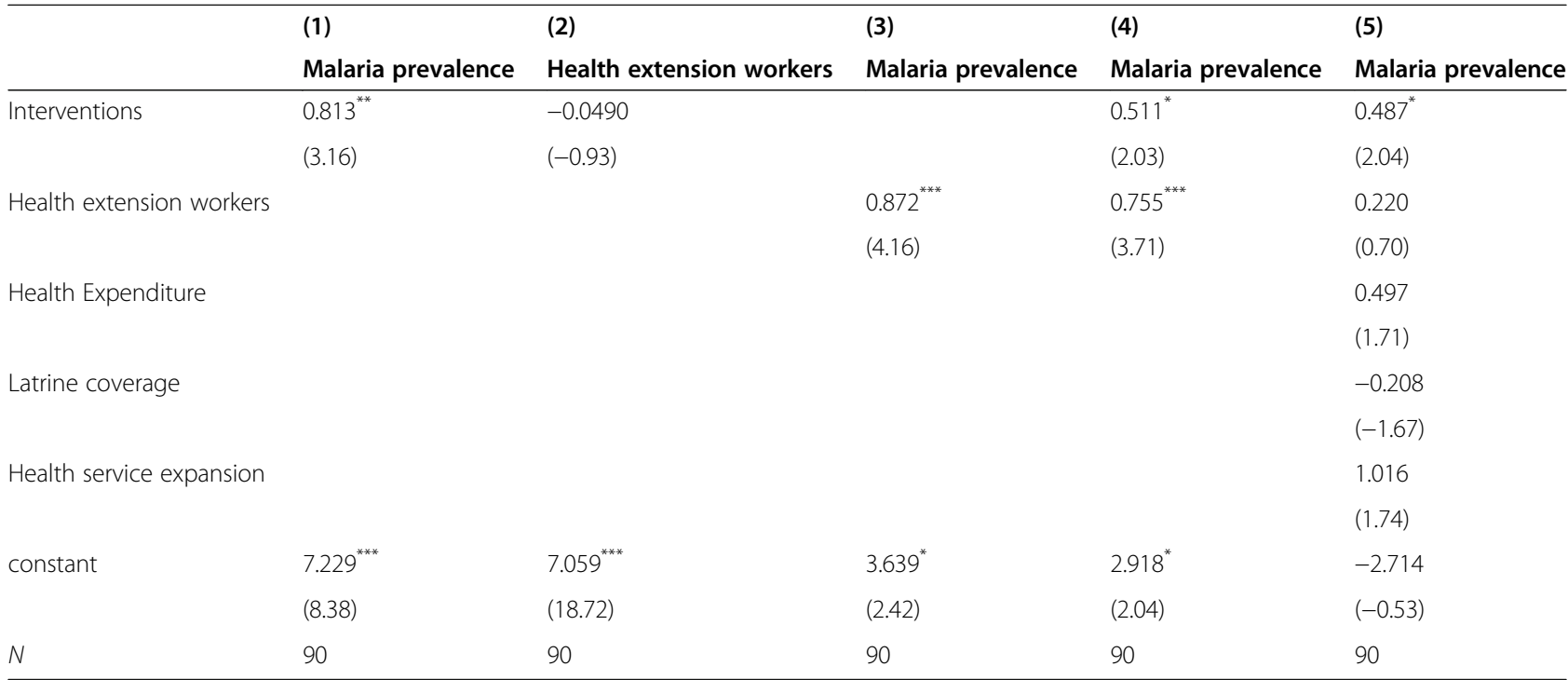

Note: $\mathrm{N}$ represents number of observations; $t$ statistics in parentheses; ${ }^{*} p<0.05,{ }^{* *} p<0.01,{ }^{* * *} p<0.001$

factors of vector control measures were implemented. The study discovered strong relationship between indoor residual spray to the outcome variable than the insecticide-treated mosquito net does $(\beta=0.70, p<$ $0.001)$ and $(\beta \mathrm{n}=0.20, p<0.05)$ respectively. The variance among principal vector control methods observed maybe because the indoor residual spray is a one-time action in a year, while ITNs is a daily activity that needs the community understanding of susceptibility and severity of the disease to take action. Thus, the study demonstrates the cumulative effect of intervention strategy better attribution in malaria prevention and control than stand alone.

\section{Discussion}

Low and middle-income countries are characterized by healthcare systems that are already fragile due to weak infrastructures, a scarcity of health workers, and limited financial resources. Malaria is yet a huge killer, representing the biggest health problem particularly in the poverty context globally. For countries with limited human and financial resources, such as Africa, prevention strategies are the utmost potential [55], which can be achieved through educating people about the program on prevention and control actions through trained professionals sustainably. In the era of pandemic diseases such as Ebola, SARS, and COVID, it is pertinent to underline how health extension workers impact to improve the relationship where they may have similar aspects and seem to have a strong potential for mutual influence. In this regard, strengthening the prevention actions aligned with the cadres of the program is critical.

Thus, the goal of the present research was to examine the interplay of strategic interventions, health extension workers, and malaria in the context of the health program. Besides, the study investigates the cumulative effect of IRS and ITNS (strategic interventions) to protect malaria. This study showed a significant relationship between IRS, ITNs, and malaria prevalence. Similar findings have also been reported a reduction in the outcome of malaria cases and malaria related-deaths due to IRS and ITNs implementation [7, 36], effective protection of ITNs use also reported [56]. Further, for malaria control, the present study proved a positive and better attribution of strategic interventions to fight against malaria. This finding is consistent with results in other studies from different malaria-endemic regions around the world, which indicates significant added protection from a combination of IRS and ITNs [26, 57].

Moreover, the study showed a positive relationship between strategic intervention and health extension workers, and health extension workers were also positively related to malaria prevalence. Furthermore, this study reported that health extension workers mediated the relationship between strategic intervention and malaria prevalence. This argument is consistent with the study which reported community health workers to improve performance efficiency $[27,58]$. Furthermore, the direct and indirect relationship through health extension workers between strategic interventions and malaria prevalence was stronger. Our result corroborated with the study finding, which reported that community health workers give their clients a way to prevent illness and treat chronic disease [45]. Hence the primary constraint, particularly in developing countries, is a severe shortage of health workers; the role of community health workers is unmeasurable in disease prevention. A positive impact of community workers on access and coverage outcomes 
of HIV patients was also reported [59]. The results of the current study show the tremendous impact of health extension workers in strengthening the relationship between strategic interventions and malaria disease and contributed to malaria prevention and control programs. However, a negative relationship between IRS, ITN and malaria was reported showing a small number of malaria cases before the implementation of these intervention [60]. The study reported the role of community health workers in building the capacity of the society and promoting patient empowerment and the entire spectrum of prevention levels [29]. There are numerous reasons why the described program has an impact on increasing the community's role in malaria control. Health extension workers can play a role in the spread of professional messages on communicable disease prevention, such as malaria, and in the outcome of infection. The program also includes the elements that have been associated with the ownership and utilization of health interventions. Thus, the present study described novel involvements for ITNs and IRS impact on malaria protection through the connection of health extension workers as mediating roles. In agreement with the role of health extension workers to influence protective ability, the community health workforce has been reported as effective to enhance health literacy and provider-patient communication [61]. Possible attribution of health extension workers in improving maternal health service also suggested [62], however, problems on health service delivery and skilled birth attendance were cited.

\section{Conclusion}

A high burden imposed from malaria on endemic regions of Ethiopia, where it accounts for the number of mortality and morbidity, mostly in pregnant women and children. However, most studies do not provide evidence on the role of health extension workers in malaria prevention and control. We provide rigorous evidence on the effects of health extension workers in improving the relationship between intervention strategy and the malaria disease. Previous research has shown the role of the health workforce in improving health outcomes. This study typically explores the specific effect of health extension workers that can act to these relationships towards prevention and control of the malaria disease. Employing structural equation modeling and the random effect model, we found a positive and incremental impact of vector control interventions on malaria. Essential questions also left that pave the way for future researchers to address, among which, providing tangible evidence on the implementation of the program, which can be solved through observation and focus group discussion with service providers and the community. It would also be of great importance to discover the cumulative effect of the total health workforce for disease protection. Also, to note the differences in the health outcome to identify the focus area to which health sector actors give attention to infectious disease prevention. Besides, we are missing information on how health extension workers run the program in society and program challenges on the implementation.

\section{Implication}

This study that has presented should be of particular interest to the organization operating in the health sector, particularly in developing countries, which are vulnerable to infectious disease. Sub-Saharan African countries are mostly experiencing the most significant public health threats, which can be preventable if appropriately addressed. The study demonstrates the provision of proper health education via health extension workers, also of potential interest for the nations which face the highest challenges of health workforce shortages. The WHO report shows the experience of a chronic deficiency of a well-trained health workforce in the world. There are 57 countries, mostly in sub-Saharan Africa, but also including Bangladesh, India, and Indonesia, that face crippling health workforce shortage [41]. To the best of knowledge, no empirical evidence available on the relationship between strategic intervention approaches and malaria as health extension workers as a mediating role. Our study finding represents the initial step towards filling this gap. The reason behind the researchers to these relationships is to give insights for policymakers to give due focus on health extension workers' effect on these relationships. Also, align with intervention provision to assure the suitable achievement to the intended goals. The generalization of the study finding and implications is not limited to the context of malaria. Rather social workers dealing with the wellbeing of the health of society, particularly infectious diseases, also be subject to the mechanisms described.

\section{Abbreviations \\ ITNs: Insecticide-treated nets; IRS: Indoor residual spray; MoH: Ministry of Health; PMI: Presidents Malaria Initiatives; RDT: Rapid Diagnostic Test; WHO: World Health Organization; HHI: Health \& Health-Related Indicators; HMIS: Health Management Information System; HEWs: Health Extension Workers; SEM: Structural Equation Modelling; REM: Random Effect Model}

\section{Acknowledgments}

The authors would like to acknowledge the editors and reviewers who have contributed their time and expertise to review the manuscript.

\section{Authors' contributions}

Conceptualization, M.A. and T.H.; methodology, T.H.; software, M.A.; formal analysis, M.A.; resources, T.H.; data curation, M.A.; writing—original draft preparation, T.H.; review and editing the manuscript for intellectual content, T.H.; supervision, T.H.; funding acquisition, all authors have read and approved the manuscript. 


\section{Funding}

This research was funded by National Natural Science Foundation of China, grant number 71473059

\section{Availability of data and materials}

Health and health-related indicators data from 2010 to 2018 are available at: (http://ghdx.healthdata.org/record/ethiopia-health-and-health-relatedindicators-2010-2011, http://ghdx.healthdata.org/record/ethiopia-health-andhealth-elated-indicators-2011-2012, http://ghdx.healthdata.org/record/ ethiopia-health-and-health-related-indicators-2012-2013, http://ghdx. healthdata.org/record/ethiopia-health-and-health-related-indicators-2013-2 014, http://ghdx.healthdata.org/record/ethiopia-health-and-health-relatedindicators-2014-2015, http://ghdx.healthdata.org/record/ethiopia-health-andhealth-related-indicators-2015-2016, http://repository.iifphc.org/bitstream/ handle/123456789/395/Health\%20and\%20Health\%20Related\%20Indicator\%2 02017.pdf?sequence=1\&isAllowed=y, http://repository.iifphc.org/bitstream/ handle/123456789/395/Health\%20and\%20Health\%20Related\%20Indicator\%2 02018.pdf? sequence=1\&isAllowed=y) all data are freely accessible. The compiled data upon which the result based could be accessed at a reasonable request.

\section{Declarations}

\section{Ethics approval and consent to participate}

"Not applicable," the research is exempt from ethical approval because of secondary data utilization: Ministry of Health; Policy, Plan, Monitoring and Evaluation Directorate, ppd@moh.gov.et

\section{Consent for publication}

Not applicable

\section{Competing interests}

Authors declare that they have no competing interest in any part of the paper, including designing, results in interpretations, and policy implications.

\section{Author details}

${ }^{1}$ School of Management, Harbin Institute of Technology, 150001 Harbin, P.R. China. ${ }^{2}$ Harbin Institute of Technology, Harbin, Heilongjiang province, China.

\section{Received: 7 September 2020 Accepted: 5 April 2021}

\section{Published online: 08 November 2021}

\section{References}

1. WHO Global Malaria Programme: Malarial case management operations manual; World Health Organization. 2009.

2. WHO Global Malaria Programme. World malaria report. Geneva: Wrold Health Organization; 2015.

3. Rowe AK. Assessing the health impact of malaria Control interventions in the MDG / sustainable development goal Era : a new generation of impact evaluations. Am J Trop Med Hyg. 2017;97(3_Suppl):6-8. https://doi.org/10.42 69/ajtmh.17-0509.

4. Animut A, Lindtjørn B. Use of epidemiological and entomological tools in the control and elimination of malaria in Ethiopia. Malaria J. 2018:1-8. https://doi.org/10.1186/s12936-018-2172-1.

5. Mathanga DP, Tembo AK, Mzilahowa T, Bauleni A, Mtimaukenena K, Taylor $T E$, et al. Patterns and determinants of malaria risk in urban and peri - urban areas of Blantyre, Malawi. Malaria J. 2016:1-9.

6. Birhanu Z, Abebe L, Sudhakar M, Dissanayake G. Malaria Related Perceptions , Care Seeking after Onset of Fever and Anti-Malarial Drug Use in Malaria Endemic Settings of Southwest Ethiopia. PLoS One. 2016;7:1-20.

7. U.S. President's Malaria Initiative: Evaluation of the Impact of Malaria Control Interventions on Malaria-Specific Morbidity and Mortality in All Ages; Ethiopia. Organizatinal Assessment report. 2015.

8. WHO Global Malaria Programme. World malaria report. Geneva: World Health Organization; 2014.

9. World Health Organization (WHO). World malaria report. Geneva; 2017

10. World Health Organization (WHO). World malaria report. Geneva; 2016.

11. Demissie Y, Ketema T. Complicated malaria symptoms associated with Plasmodium vivax among patients visiting health facilities in Mendi town Northwest Ethiopia. BMC Infectious Dis. 2016:1-8. https://doi.org/10.1186/ s12879-016-1780-z
12. Kayentao K, Florey LS, Mihigo J, Doumbia A, Diallo A, Koné D. Impact evaluation of malaria control interventions on morbidity and all - cause child mortality in Mali , 2000-2012. Malaria J. 2018:1-15. https://doi.org/1 0.1186/s12936-018-2573-1.

13. Alelign A, Tekeste Z, Petros B. Prevalence of malaria in Woreta town, Amhara region, Northwest Ethiopia over eight years. BMC Public Health. 2018;18:990.

14. President's Malaria Initiative: Malaria Operational Plan; Addis Ababa, Ethiopia. 2016. Available from: https://www.pmi.gov/where-we-work/ethiopia\%0A, https://www.pmi.gov/docs/default-source/default-document-library/malariaoperational-plans/fy16/fy-2016-ethiopia-malaria-operational-plan.pdf?sfvrsn=5

15. Federal Ministry of Health Ethiopia. Health \& Health-Related Indicators 2016/ 2017. Addis Ababa: Policy Planning Directorate, FMoH; 2017.

16. Tesfay K, Yohannes M, Bayisa S. Trend analysis of malaria prevalence in Raya Azebo district, Northern Ethiopia : a retrospective study. BMC Research Notes. 2018:1-5. https://doi.org/10.1186/s13104-018-4003-4.

17. Federal Ministry of Health Ethiopia. Health Sector Development Programme IV (2010/11-2014/15). Addis Ababa: Planning and Program Department, Ministry of Health; 2010; 2014.

18. Sector H, Programme D. Federal ministry of health Ethiopia: health Sector development Programme IV. Addis Ababa: Annual Performance Report, Ministry of Health, 2014; 2014.

19. Seyoum D, Speybroeck N, Duchateau L, Brandt P. Long-lasting insecticide net ownership, access and use in Southwest Ethiopia: a community-based cross-sectional study. Int J Environ Res Public Health. 2017;14:1312.

20. Watiro $\mathrm{AH}$. Insecticide-treated net ownership and utilization and factors that influence their use in Itang, Gambella region, Ethiopia: cross-sectional study. Risk Manage Healthc Policy. 2016;9:101-12.

21. Alemu MB, Asnake MA, Lemma MY, Melak MF. Utilization of insecticide treated bed net and associated factors among households of Kola Diba town, North Gondar, Amhara region, Ethiopia. BMC Research Notes. 2018: 1-5. https://doi.org/10.1186/s13104-018-3697-7.

22. Birhanu Z, Abebe L, Sudhakar M, Dissanayake G, Yihdego Y. Access to and use gaps of insecticide- treated nets among communities in Jimma Zone, Southwestern Ethiopia: baseline results from malaria education interventions. BMC Public Health. 2015:15:1304.

23. Haji Y, Fogarty AW, Deressa W. Prevalence and associated factors of malaria among febrile children in Ethiopia : A cross-sectional health facility-based study. Acta Tropica. 2016;155:63-70. https://doi.org/10.1016/j.actatropica.201 5.12.009.

24. Tassew A, Hopkins R, Deressa W. Factors influencing the ownership and utilization of long-lasting insecticidal nets for malaria prevention in Ethiopia. Malar J. 2017:16:262

25. Munga S, Kimwetich Z, Atieli F, Vulule J, Kweka EJ. Knowledge and perceptions about indoor residual spray for malaria prevention in mumberes division, Nandi county in central province of Kenya. Tanzania J Health Res. 2017:19(4):1-9.

26. Fullman N, Burstein R, Lim SS, Medlin C, Gakidou E. Nets, spray or both? The effectiveness of insecticide-treated nets and indoor residual spraying in reducing malaria morbidity and child mortality in sub-Saharan Africa. Malaria J. 2013:12:62

27. Johns B, Yihdego Y, Kolyada L, Dengela D, Chibsa S, Dissanayake G, et al. Indoor residual spraying delivery models to prevent Malaria : comparison of community- and district-based approaches in Ethiopia. Global Health: Scince and Practice. 2016:4(4):529-41.

28. Dussault G, Franceschini MC. Human Resources for Health imbalances in the distribution of the health workforce. 2014;(June).

29. Balcazar $\mathrm{H}$. Community health workers can be a public health force for change in the United States: three actions for a new paradigm. Am J Public Health. 2011;101(12):2199-203.

30. Suryana NA, Agustina ZA, Wardiyanto B. Assessment of health human resources policy for health workers at community health centers in Eastern Indonesia. Int J Adv Sci Res Eng. 2019;5(4):94-101.

31. Ethiopia National Malaria Indicators Survey: Ethiopian Public Health Institute; Addis Ababa Ethiopia. 2015.

32. President 'S Malaria Initiative. Malaria Operational Plan; Ethiopia. 2017.

33. Federal Democratic Republic of Ethiopia Ministry of Health. NATIONAL MALARIA STRATEGIC PLAN: 2017-2020. Addis Ababa: Disease Prevention and Control Directorate; 2017.

34. Doda Z, Solomon T, Loha E, Gari T, Lindtjørn B. A qualitative study of use of long - lasting insecticidal nets ( LLINs) for intended and unintended 
purposes in Adami Tullu, East Shewa Zone, Ethiopia. Malaria J. 2018:1-14. https://doi.org/10.1186/s12936-018-2209-5.

35. Watiro AH, Awoke W. Insecticide-treated net ownership and utilization and factors that influence their use in Itang, Gambella region, Ethiopia: crosssectional study. Risk Manage Healthc Policy. 2016;9:101-12.

36. WHO Global malaria programme: World Malaria Report; World Health Organization, Geneva, Switzerland. 2013

37. Zewde A, Irish S, Woyessa A, Wuletaw $\mathrm{Y}$, Nahusenay H, Abdelmenan S, et al. Knowledge and perception towards net care and repair practice in Ethiopia. Malar J. 2017;16:396

38. Federal Democratic Republic of Ethiopia, Ministry of Health. The Health Sector Transformation Plan (HSTP) 2010/11-2014/15, strategic themes of HSTP. Addis Ababa: Planning and Program Department.

39. Rosenthal BEL, Brownstein JN, Rush CH, Hirsch GR, Willaert AM, Scott JR, et al. Community health workers: part of the solution. Health Aff. 2010;7:1338-42.

40. Programme A. Taking stock: Health worker shortages and the response to AIDS. 2006;1-16.

41. World T. Report H. for health; 2006.

42. World Health Organization. Human resources for health, toolkit on monitoring health systems strengthening. 2009.

43. Ingabire CM, Alaii J, Hakizimana E, Kateera F, Muhimuzi D, Nieuwold I, et al. Community mobilization for malaria elimination: application of an open space methodology in Ruhuha sector, Rwanda. Malaria J. 2014;13(1):1-8.

44. World Health Organization. World Health Report 2006. World Health Report. 2006;19(3):237 Available from: http://www.who.int/whr/2006/whr06_en.pdf.

45. Practice C, Nichols DC, Berrios C, Samar H. Texas ' community health Workforce : from state health promotion policy to. Public health research, Practice and Policy. 2005;2(November):1-7.

46. The implementation of Ethiopia's Health Extension Program. Ethiopia Good Practice. Addis Ababa: ALULA SEBHATU; 2008.

47. Health Sector transformation plan (HSTP). Federal Minstry of Health, 2015; Addis Ababa, Ethiopia,. 2015.

48. Lu Y, Zhou L. Capabilities as a mediator linking resources and the international performance of entrepreneurial firms in an emerging economy. J Int Business Stud. 2009;41(3):419-36. https://doi.org/10.1057/ jibs.2009.73.

49. Schmidheiny K. Short Guides to Microeconometrics. Panel Data: Fixed and Random Effects. Vol. 2, Unversit"at Basel; 2018.

50. Ethiopia National Malaria Indicators Survey: Ethiopian Public Health Institute; Addis Ababa Ethiopia. 2011.

51. Federal Democratic Republic of Ethiopia Ministry of Health. National Malaria Strategic Plan 2014-2020. Addis Ababa: Malaria Control Programme; 2014.

52. Bell A. Explaining fixed effects: random effects modeling of time-series cross-sectional and panel data*. European political science association. 2015 3(1):133-53.

53. Mackinnon DP, Fairchild AJ, Fritz MS. Mediation analysis. The Annual Review of Psychology. 2007;58(1):593-614. https://doi.org/10.1146/annurev.psych. 58.110405 .085542

54. Dawit Getnet Ayele TTZ and HGM. The risk factor indicators of malaria in Ethiopia. Int J Med Medical Sci. 2013:5(7):335-47.

55. Di Gennaro F, Marotta C, Locantore P, Pizzol D, Putoto G. Malaria and COVID-19: common and different findings. Trop Med Infect Dis. 2020;5:141.

56. Saha A, Sarker M, Kabir M, Lu G, Müller O. Knowledge, attitudes, and practices regarding malaria control among the slash and burn cultivators in Rangamati Hill tracts of Bangladesh. Malaria J. 2019:1-9. https://doi.org/1 0.1186/s12936-019-2849-0.

57. West PA, Protopopoff N, Wright A, Kivaju Z, Tigererwa R, Mosha FW, et al. Indoor residual spraying in combination with insecticide-treated nets compared to insecticide-treated nets alone for protection against malaria: a cluster randomised trial in Tanzania. PLoS Med. 2014;11(4):e1001630. https:// doi.org/10.1371/journal.pmed.1001630.

58. Salam RA, Das JK, Lassi ZS, Bhutta ZA. Impact of community-based interventions for the prevention and control of malaria on intervention coverage and health outcomes for the prevention and control of malaria. Infect Dis Poverty. 2014;3(1):1-15.

59. Alamo S. Task-Shifting to Community Health Workers: Evaluation of the Performance of a Peer-Led Model in an Antiretroviral Program in Uganda. Aids Patient Care STDs. 2012;26(2).

60. Mohammed MA, Hong T. Journal of infection and public health role of vector control in fighting against malaria : evidence from Ethiopian health- related indicators. J Infect Public Health. 2021;14(4):527-32. https://doi.org/1 0.1016/j.jiph.2020.12.002.

61. Brownstein JN, Bone LR, Dennison CR, Hill MN, Kim MT, Levine DM. Community health workers as interventionists in the Prevention and Control of heart disease and stroke. Am J Prev Med. 2005;29:581.

62. Medhanyie A, Spigt M, Kifle Y, Schaay N, Sanders D, Blanco R, et al. The role of health extension workers in improving utilization of maternal health services in rural areas in Ethiopia : a cross sectional study. BMC Health Services Res. 2012;352(12):1472-6963 Available from: BMC Health Services Research.

\section{Publisher's Note}

Springer Nature remains neutral with regard to jurisdictional claims in published maps and institutional affiliations.
Ready to submit your research? Choose BMC and benefit from:

- fast, convenient online submission

- thorough peer review by experienced researchers in your field

- rapid publication on acceptance

- support for research data, including large and complex data types

- gold Open Access which fosters wider collaboration and increased citations

- maximum visibility for your research: over $100 \mathrm{M}$ website views per year

At BMC, research is always in progress.

Learn more biomedcentral.com/submissions 